ISSN: $1130-2887$

\title{
A MAYORES PREVISIONES... RESULTADOS IMPREVISTOS: REFORMA JUDICIAL EN AMÉRICA LATINA -INDICIOS SOBRE COSTA RICA
}

The best laid schemes... gang aft a-gley: judicial reform in

Latin America -evidence from Costa Rica

\author{
Bruce M. Wilson, Juan Carlos Rodríguez Cordero y Roger HandBerg \\ University of Central Florida/Consorcio Juridico Metropolitano, Costa Rica/University of Central Florida \\ 两bwilson@mail.ucf.edu \\ Mexergo@law.com \\ \hanbgerg@mail.ucf.edu
}

BIBLID [1130-2887 (2005) 39, 97-123]

Fecha de recepción: noviembre del 2004

Fecha de aceptación y versión final: diciembre del 2004

RESUMEN: A partir de la década de 1980, e intensificándose en la década de 1990, las instituciones financieras internacionales (IFIs), las organizaciones no gubernamentales (ONGs) y las agencias de desarrollo destinaron gran cantidad de recursos a programas de reforma judicial y de Administración de justicia en prácticamente todos los países de América Latina y el Caribe. Se suponía que la modernización de los sistemas judiciales favorecería las estrategias de libre mercado y desarrollo económico. Este artículo analiza el impacto de dos temas centrales de la reforma judicial, el acceso a la justicia y la independencia judicial, en relación con la formulación de políticas económicas en Costa Rica. Nuestro argumento es que hay una gran posibilidad de que aparezcan discordancias entre las expectativas de los patrocinadores acerca del impacto económico de la reforma judicial y los resultados observados.

Palabras clave: reforma judicial, Poder Judicial, Sala Iv, Costa Rica, independencia judicial.

ABSTRACT: Starting in the 1980s, and accelerating through the 1990s, international financial institutions (IFIs), non-governmental organizations (NGOs) and development agencies funnelled considerable resources into judicial reform and rule of law programmes in virtually every Latin American and Caribbean country. The assumption was that reformed court systems would foster free market economic development strategies. This article examines the impact of two frequently advocated aspects of judicial reform, judicial access and judicial independence, on 
BRUCE M. WILSON, JUAN CARLOS RODRÍGUEZ CORDERO Y ROGER HANDBERG

A MAYORES PREVISIONES... RESULTADOS IMPREVISTOS:

REFORMA JUDICIAL EN AMÉRICA LATINA -INDICIOS SOBRE COSTA RICA

economic policy making in Costa Rica. We argue that there is a potentially significant disjuncture between the sponsors' expectations of the judicial reforms' economic impact and the observed outcomes.

Key words: judicial reform, Judiciary, $4^{\text {th }}$ Chamber, Costa Rica, judicial independence.

\section{INTRODUCCIÓN ${ }^{1}$}

Después de casi doscientos años de hibernación política, muchas Cortes Supremas de América Latina abandonaron su actitud pasiva y asumieron funciones más activas en la vida política de sus respectivos países. Además de que han sido factores domésticos los que han impulsado muchas de las reformas legales en esa dirección, en los últimos veinte años varias instituciones financieras internacionales (IFIs), organizaciones no gubernamentales (ONGS) y agencias de desarrollo internacional han destinado cientos de millones de dólares para promover y favorecer la reforma judicial como solución a muchos de los problemas sociales y económicos en toda América Latina ${ }^{2}$. Estos programas han adquirido tal protagonismo, que para las agencias de desarrollo la Administración de justicia ha sido considerada como «la solución a los problemas mundiales ${ }^{3}$. La razón subyacente es muy sencilla: la independencia judicial y el acceso a la justicia son cruciales para la gobernabilidad, pues garantizan el respeto a los derechos conferidos por el ordenamiento jurídico a los ciudadanos. Entre las agencias de desarrollo ha gozado de gran acogida el argumento según el cual para facilitar las reformas económicas $:$ ? requiere un Poder Judicial independiente que provea soporte legal a las iniciativas gubernamentales tendentes a reformar las moribundas economías, mediante un nuevo enfoque en el mercado que sustituya al normativismo gubernamental. En consecuencia, a los ojos de muchos de los encargados de generar políticas y de las organizaciones de desarrollo, los tribunales de justicia deben asumir una función prominente para asegurar la estabilidad política y el progreso económico.

La idea de vincular la Administración de justicia con el desarrollo económico precede a la etapa actual de la reforma judicial. Rick Messick, del Banco Mundial, ha documentado la larga historia intelectual que relaciona el desempeño económico con la

1. «La independencia judicial es el reflejo de una institucionalidad fuerte que refleja libertad personal y prosperidad». Juez Stephen G. Beyer, Suprema Corte de los Estados Unidos. Traducido al español por Hugo Picado León. Los autores agradecen a las siguientes personas por sus valiosos comentarios a los borradores previos de este artículo: R. Messick, L. Hammergren, L. F. Solano Carrera, presidente de la Sala IV, R. Wilson, K. Hamann, R. Sieder y a las referencias anónimas de JLAS. También agradecemos a J. Collins por su asistencia en la investigación. R. Wilson desea agradecer a la Oficina de Apoyo a la Investigación de la Universidad Central de Florida, por financiar parte de este trabajo mediante la beca n. ${ }^{\circ} 11-80-936 / 11809002$.

2. P. DOMingo y R. Sieder (2001); L. HAMmergren (1998). Se han desarrollado muchos programas de Administración de justicia en otras partes del mundo, especialmente en los antiguos países comunistas (USAID, 2002; J. FAUNDEZ, 1997: 1-24).

3. T. CAROTHERS (2001a: 95). 
REFORMA JUDICIAL EN AMÉRICA LATINA -INDICIOS SOBRE COSTA RICA

Administración de justicia ${ }^{4}$. Messick señala que esta relación fue planteada inicialmente en el siglo XV por el jurista inglés Sir John Fortescue, luego en el siglo XVIII por el economista escocés Adam Smith, siguiendo en el siglo XIX con el sociólogo alemán Max Weber, y actualmente por economistas neo-institucionales como Douglas North, los cuales han subrayado el importante vínculo entre el buen funcionamiento del sistema judicial, el imperio de la ley y el desarrollo económico bajo un sistema de libre mercado. De acuerdo con ese razonamiento, que actualmente es asumido por las agencias de desarrollo internacional, cualquier país que lleve a cabo las reformas al sistema judicial recomendadas por esas instituciones, como consecuencia, experimentará un desarrollo previsible de la economía de libre mercado.

Este artículo analiza las motivaciones y expectativas del Banco Mundial al financiar los proyectos de reforma judicial. Por su énfasis en la independencia judicial y en las reformas económicas, el Banco Mundial resulta representativo de muchas otras organizaciones. No obstante, según demostraremos, este razonamiento no siempre se corresponde con los resultados obtenidos. Lo ilustraremos analizando el impacto de la reforma judicial en Costa Rica, en particular la creación de la Sala Constitucional (Sala IV) en 1989, y su efecto sobre la autonomía gubernamental para generar políticas. Hemos identificado dos tendencias argumentativas contrarias a los defensores de la reforma judicial. Primero, que la independencia judicial es importante y necesaria para la actividad judicial, pero no suficiente. El caso costarricense comprueba que aunque la independencia judicial precedió a la reforma de la década de 1980, fue insuficiente para que la Corte Suprema asumiera un papel activo en el control de las acciones de las distintas ramas del gobierno. En todo caso, lo que en efecto vino a marcar una crucial diferencia fueron los mecanismos de acceso a la justicia introducidos mediante las reformas. Ello nos lleva al segundo argumento. Cuando este acceso se hace más amplio, también resulta más difícil predecir el contenido sustantivo de las sentencias de la Corte. No hay motivo para asumir que ampliar el acceso necesariamente resultará en decisiones que favorezcan las reformas de libre mercado. Las cortes constitucionales se encuentran sujetas a las normas establecidas en las respectivas constituciones, y si la Constitución tiene una orientación estatista, la ampliación del acceso bien podría propiciar decisiones que limiten las oportunidades del gobierno para llevar a cabo reformas de libre mercado.

Por tal razón, examinamos el impacto de la reforma judicial costarricense de 1989 sobre el proceso de generación de políticas económicas y comparamos sus resultados con las expectativas del Banco Mundial sobre las consecuencias económicas de esa reforma. El artículo se desarrolla de la siguiente manera: la primera sección examina la convergencia de la Administración de justicia entendida por las IFIs y las ONGs. La segunda sección introduce como caso de estudio la reforma judicial en Costa Rica, particularmente la creación de una cámara constitucional (Sala IV) en la Corte Suprema. La siguiente sección muestra el grado en que las reformas en Costa Rica se corresponden con los objetivos previstos por el Banco Mundial. La última sección estudia el funcionamiento

\section{R. MessicK (1999).}


de la nueva sala y examina la relevancia de algunas de sus resoluciones típicas y notables. En la conclusión indicamos nuestro acuerdo con el Banco Mundial y con otras agencias internacionales en cuanto a la importancia que se debe dar a las reformas de la Administración de justicia en los países latinoamericanos, pero discrepamos con las predicciones de esos organismos según las cuales las reformas necesariamente facilitarían el desarrollo económico del libre mercado.

\section{PATROCINADORES INTERNACIONALES Y LOS PROGRAMAS DE REFORMA JUDICIAL}

Aunque frecuentemente la iniciativa de la reforma judicial en América Latina surge localmente, las organizaciones internacionales también han aportado considerables recursos, tanto financieros como técnicos's. Según Thomas Carothers, estas organizaciones se han inscrito en proyectos de reforma a la Administración de justicia motivados por objetivos generales tales como impulsar la democratización, el desarrollo económico, los derechos humanos o la justicia social, o bien el refuerzo del derecho internacional ${ }^{6}$.

A pesar del acuerdo general sobre la urgente necesidad de la reforma judicial, no hay consenso sobre la forma que ella debe asumir. Los patrocinadores internacionales tendían a enfatizar distintos aspectos de la reforma judicial sin tomar en cuenta los objetivos de otros patrocinadores ${ }^{7}$. Sin embargo, desde inicios de la década de 1990, algunas agencias internacionales comenzaron a fusionar sus objetivos sobre reforma judi$\mathrm{cial}^{8}$. Por ejemplo, las metas estrictamente económicas del Banco Mundial se han ido extendiendo hasta comprender asuntos relativos a la democracia y a la sociedad civil ${ }^{9}$. De manera similar, los objetivos democratizadores de los programas de reforma judicial impulsados por la estadounidense Agencia Internacional para el Desarrollo (USAID)

5. La magnitud del financiamiento internacional a programas de Administración de justicia por parte del Banco Mundial, la USAID y el Banco Interamericano de Desarrollo, ha sido bien documentada por P. DOMINGO y R. Sieder (2001).

6. T. CAROTHERS (2001b).

7. De hecho, en algunos casos los programas de reforma judicial de una agencia han obstruido o impedido reformas promovidas por otras agencias. T. CAROTHERS (2001b: 11 ) señala que el programa de una agencia tendente a ampliar el acceso a la justicia puede perjudicar el propósito de otra agencia que procure agilizar los procesos judiciales. La falta de coordinación entre agencias puede causar otros problemas. Por ejemplo, cuando distintas agencias promueven sus propias reformas sin tomar en cuenta los otros programas; esto ocurrió en 1996 cuando una reforma a la policía guatemalteca financiada con recursos estadounidenses perjudicó en varios aspectos los avances de una iniciativa de financiamiento español.

8. Estas reformas son ampliamente referidas en la actualidad como programas de Administración de justicia (Rule of Law). Aunque en este artículo se utilicen indistintamente esta acepción o la de reforma judicial (judicial reform), advertimos que la primera es más frecuentemente utilizada en referencia a reformas más amplias que aquellas estrictamente restringidas a lo meramente institucional. Es a este sentido estricto al que se define como reforma judicial (P. DOMINGO y R. SiEDER, 2001).

9. M. DAKOLIAS (2001). 
ahora incluyen un distinto énfasis vinculado al desarrollo económico de libre mercado. Según la USAID un «sistema judicial efectivo es esencial para el desarrollo económico y para el bienestar de una sociedad $»^{10}, \mathrm{y}$ «la independencia judicial se sustenta en el buen funcionamiento del Poder Judicial y constituye la piedra angular de una sociedad democrática, de mercado, basada en el imperio de la ley» ${ }^{11}$. Actualmente la USAID entiende su desafío como «diseñar programas de Administración de justicia que promuevan y aseguren el crecimiento económico» ${ }^{12}$.

Mientras que la USAID tiene una de las más extensas tradiciones en el financiamiento de programas para el mejoramiento de la Administración de justicia en América Latina, aportando más de U\$S 200 millones para reformas desde 1985 hasta $1995^{13}$, el Banco Mundial y, en menor grado, el Banco Interamericano para el Desarrollo (BID), también han sido líderes en el patrocinio de estos proyectos. Estas dos organizaciones, en conjunto, han destinado más de U\$S 300 millones a proyectos de reforma judicial entre 1992 y $1997^{14}$. El BID persigue objetivos de desarrollo económico mediante sus 14 proyectos de reforma judicial que incrementen la eficacia de los sistemas judiciales latinoamericanos y extiendan el acceso a la justicia ${ }^{15}$.

Otro reciente patrocinador de proyectos de mejoramiento en la Administración de justicia es el Programa de Desarrollo de las Naciones Unidas (PNUD), que inicialmente tuvo por objeto «detener las raíces de los conflictos violentos... [y] asegurar la justicia y la reconciliación en las situaciones de post-conflicto» ${ }^{16}$. Más recientemente, el PNUD ha extendido ese cometido al avance de la gobernabilidad «democrática y la defensa de los derechos fundamentales» para incluir la promoción del buen funcionamiento de los sectores judiciales a fin de facilitar el desarrollo económico ${ }^{17}$. Casi todas estas agencias esperan que sus programas de mejoramiento en la Administración de justicia ayuden tanto a profundizar la democracia como a facilitar el desarrollo de la economía de libre mercado ${ }^{18}$. Luis Salas argumenta que «en el corazón de este nuevo movimiento de reforma legal se encuentra una creencia en la inevitabilidad de la integración económica global y la evolución de sistemas legales para enfrentar los desafíos de las nuevas economías neoliberales de mercado» ${ }^{19}$.

10. P. VAKY (1998: 137).

11. USAID (2002). del 2003.

12. USAID. Rule of Law. En http://www.usaid.gov/democracy/rol.html, consultado el 12 de mayo

13. J. CoRrea Sutil (1999: 256).

14. P. AMSTRONG (1997).

15. Un significativo porcentaje del programa judicial del BID se ha destinado a la construcción de edificios para los tribunales de justicia en zonas rurales, para facilitar el acceso a la justicia a personas pobres que viven al margen de las ciudades (F. CARRILLO, 1998: 153; P. DOMINGO y R. SIEDER, 2001).

16. PNUD (2001).

17. J. OBANDO (1998: 143-144).

18. T. CAROTHERS (2001: 11).

19. L. SALAS (2001: 17). 


\section{El Banco Mundial y la Administración DE JUSTICIA}

Este artículo se refiere de manera específica a los esfuerzos de reforma judicial del Banco Mundial. De varias formas el Banco Mundial resume las ideas e ideales de otras agencias de desarrollo. Se trata de uno de las más importantes promotores de la reforma judicial en América Latina, aun cuando su preocupación por el tema surgió relativamente tarde en comparación con otras IFIs y ONGs. Su interés por la reforma judicial surge como consecuencia colateral de la severa crisis económica sufrida por América Latina y por la mayor parte de los países menos desarrollados durante las décadas de 1980 y 1990. El Banco respondió a la crisis económica con préstamos condicionados a programas de ajuste estructural (PAE). Estos préstamos obligaban a países en severas crisis económicas a reducir significativamente el papel económico del Estado y a promover un ambiente de mercado favorable para el desarrollo de la empresa privada.

Sin embargo, varios estudios revelan que el Banco Mundial, así como muchas otras IFIs, han tenido un historial notablemente pobre en lo que respecta al seguimiento y al cumplimiento obligatorio de las referidas condiciones de préstamo ${ }^{20}$. El bajo nivel de cumplimiento condujo al Banco Mundial a introducir el concepto de «gobernanza» en las discusiones sobre desarrollo desde finales de la década de 1980. Esta terminología apareció primero en un informe del Banco Mundial sobre África Subsahariana en 1989 y fue explícitamente definido y formalmente aceptado tres años después ${ }^{21}$. El Banco define como «gobernanza» la manera en que el poder es ejercido en el manejo de los recursos económicos y zociales para el desarrollo de un país. Buena gobernanza se resume como la previsible, abierta y clara formación de políticas públicas (es decir, mediante un proceso transparente); una burocracia imbuida en un espíritu de profesionalidad, una.rama ejecutiva del gobierno que rinda cuentas sobre sus acciones; y una sociedad civil fuerte que participe en los asuntos públicos y todo comportamiento bajo el imperio de la ley ${ }^{22}$.

Así, el Banco asumió la necesidad de la reforma judicial al reconocerla como componente fundamental de la buena «gobernanza», que por sí misma es fundamental para la eficaz y eficiente realización de los programas de desarrollo económico y social impulsados por el Banco.

El movimiento por la reforma judicial en América Latina, normalmente, ha abarcado a todo el sistema judicial (incluyendo la legislación civil y penal, así como la estructura constitucional de los tribunales) y ha afectado a prácticamente todos los países del hemisferio. Sin embargo, el particular interés del Banco Mundial por la reforma judicial no es tan amplio. Las normas constitutivas del Banco delimitan sus acciones; así, aunque puede reconocer que los derechos humanos y los problemas económicos son

20. Ver S. HaGgark (1986); M. Kahler (1989: 139-160).

21. WORLD BANK (1992).

22. Esta particular publicación es adaptada de un documento de la junta del Banco Mundial que fue firmado por los Directores Ejecutivos del Banco a finales de 1993, y que forma parte de la política del Banco Mundial (WORLD BANK , 1994). 
BRUCE M. WILSON, JUAN CARLOS RODRÍGUEZ CORDERO Y ROGER HANDBERG A MAYORES PREVISIONES... RESULTADOS IMPREVISTOS:

REFORMA JUDICIAL EN AMÉRICA LATINA -INDICIOS SOBRE COSTA RICA

componentes de la ineficiencia judicial, no puede abordarlos de manera directa. El Banco únicamente está autorizado a suscribir programas de reforma legal que «resulten relevantes para el desarrollo económico de los países»»3. Las normas explícitamente le prohíben «interferir en los asuntos de política interna del país» y solamente le permiten tomar en cuenta «consideraciones de carácter económico» para sus decisiones de financiamiento ${ }^{24}$. De esta forma, en términos de reforma judicial, el Banco no está autorizado a financiar programas que incluyan reformas a códigos penales, al entrenamiento de fuerzas policiales y de jueces penales, o al manejo de instituciones carcelarias, aunque esos aspectos del sistema judicial sean muy ineficientes y requieran profundas reformas ${ }^{25}$.

El principio subyacente a los programas de reforma judicial impulsados por el Banco es que la creación de un accesible y eficiente sector judicial es necesaria para el manejo de las más complejas transacciones, como adquisiciones y fusiones, que aparecerán como resultado de las reformas del mercado. El Poder Judicial puede impactar las transacciones del mercado garantizando costos predecibles en la resolución de disputas y è efectivo cumplimiento de las normas sobre la propiedad y los contratos. En este contexto, el Poder Judicial tiene que jugar un papel fundamental en el crecimiento de los mercados. Los gobiernos, en consecuencia, están forzados a atender la crisis del sistema judicial a fin de crear un ambiente atractivo para la inversión extranjera y para el fortalecimiento de los derechos individuales ${ }^{26}$.

Según Rick Messick, «las reformas judiciales son parte de un más amplio esfuerzo por lograr que los sistemas legales en países en vías de desarrollo y aquellos en transición, sean más amigables al mercado» ${ }^{27}$. María Dakolias, una especialista en sector judicial del Banco Mundial, argumenta que el «buen funcionamiento del Poder Judicial es importante para el desarrollo económico». Ella sigue diciendo: «actualmente el Poder Judicial [en América Latina y el Caribe] es incapaz de asegurar una eficiente y predecible resolución de conflictos que asegure los derechos individuales y de propiedad» y de esa manera constituye un gran obstáculo para el desarrollo económico y social ${ }^{28}$.

En tanto, la reforma judicial ha tomado diferentes dimensiones a lo largo de América Latina, Dakolias identifica cinco áreas indispensables para la reforma judicial tendente a alcanzar objetivos de desarrollo económico, que también forman parte de programas de Administración de justicia de otras agencias ${ }^{29}$. Éstas son: independencia del Poder Judicial; acceso a la justicia; eficiencia administrativa en la tramitación de los asuntos y en el funcionamiento de los tribunales; educación legal de los jueces y de la sociedad y profesionalización de los colegios o asociaciones de abogados.

\author{
23. I. SHIHATA (1995: 170). \\ 24. WORLD BANK (1992). \\ 25. R. MESSICK (1999). \\ 26. E. Buscaglia y M. Dakolias (1996: 41). \\ 27. R. MESSICK (1999: 119). \\ 28. M. DAKOLIAS (1996: 319). \\ 29. M. DAKOLIAS (1996: 7-62).
}


BRUCE M. WILSON, JUAN CARLOS RODRÍGUEZ CORDERO Y ROGER HANDBERG A MAYORES PREVISIONES... RESULTADOS IMPREVISTOS: REFORMA JUDICIAL EN AMÉRICA LATINA -INDICIOS SOBRE COSTA RICA

$\mathrm{La}$ independencia del Poder Judicia ${ }^{30}$ requiere la despolitización de los procesos por medio de los cuales el personal judicial es nombrado y removido. El Poder Judicial también debería gozar de independencia administrativa y financiera, sin intromisiones del Poder Ejecutivo. Las Cortes deben tener el poder suficiente para declarar la inconstitucionalidad de acciones ejecutivas y legislativas cuando resulte procedente ${ }^{31}$. La independencia judicial, según se argumenta, permitiría una «judicatura que tome decisiones acordes con la ley y no basadas en factores internos o externos». La independencia también permitiría cambiar «la percepción pública sobre el comportamiento corrupto de los jueces ${ }^{32}$. Se requiere un Poder Judicial independiente para limitar las acciones de lo que, desde el punto de vista del Banco, son regímenes excesivamente estatistas en muchos de los países menos desarrollados. La independencia judicial, según se dice, permitiría la activación de las Cortes a fin de desafiar el excesivo intervencionismo del Estado en la economía y, consecuentemente, impulsaría el desarrollo económico y social en mercados libres de la intervención estatal.

La segunda área de la reforma judicial corresponde al acceso a la justicia, referido a la necesidad de abrir el sistema judicial a todos los ciudadanos, ricos o pobres, que requieran reparación legal a sus derechos. Algunas soluciones propuestas a este problema incluyen la creación de mecanismos alternativos de solución de conflictos y la transferencia de asuntos no contenciosos a agencias administrativas, permitiendo a los tribunales dedicar más tiempo a la resolución de asuntos contenciosos ${ }^{33}$.

La tercera área abarcada por la reforma es la eficiencia en la tramitación de casos y en la administración de los tribunales. El significativo atraso en la tramitación de los casos y la excesiva duración de ..ss procesos judiciales propicia la corrupción en el Poder Judicial y genera una extendida desconfianza hacia el sistema ${ }^{34}$, además de impedir el efectivo acceso a la justicia a los sectores más pobres de la población, que no pueden pagar los respectivos costes. Estas ref ormas son necesarias para proveer a los ciudadanos de una mayor confianza en el sistema judicial, la cual generalmente es baja en América Latina ${ }^{35}$.

En cuarto lugar, es necesario educar a los jueces, especialmente a quienes actualmente ocupan esos cargos, acerca del correcto funcionamiento del sector judicial y acerca de sus papeles en el proceso. El público también requiere ser educado acerca de sus

30. La dificultad de medir la independencia judicial constituye un problema que ha requerido del concurso de muchos especialistas (L. HAMMERGREN, s./f.; Judicial Independence: What It Is, How It Can Be Measured, Why It Occurs. En http://www1.worldbank.org/publicsector/test/oldlegal/judicialindependence.htm, consultado el 19 de septiembre del 2003; J. VERNER, 1984: 463-506).

31. R. MESSICK (1999: 118).

32. M. DAKOlias (1996).

33. R. MESSiCK (1999: 118); L. HAMMERGREN (1998); USAID (s./f.).

34. E. BusCAGLia et al. (1995: 2).

35. Un estudio de 1995 sobre «Competitividad en el Mundo» sitúa los sistemas judiciales latinoamericanos, con excepción de Chile, entre los que integran el 20\% más bajo del mundo. El estudio evalúa los sistemas judiciales en términos de eficiencia, opinión de los usuarios y confianza pública. E. BusCAGLiA et al. (1995: 2). 
BRUCE M. WILSON, JUAN CARLOS RODRÍGUEZ CORDERO Y ROGER HANDBERG

A MAYORES PREVISIONES... RESULTADOS IMPREVISTOS:

REFORMA JUDICIAL EN AMÉRICA LATINA -INDICIOS SOBRE COSTA RICA

derechos y sobre cómo pueden utilizar el sistema para su protección. Finalmente, el Banco identifica la necesidad relativa de profesionalizar los colegios o asociaciones de abogados en toda América Latina ${ }^{36}$.

Muchos de los argumentos del Banco Mundial a favor de sus proyectos de reforma judicial resultan muy atractivos, especialmente al observar las condiciones de los sistemas judiciales latinoamericanos previas a la reforma. Pero mientras es cierto que actualmente pocos cuestionan la importancia de la reforma judicial para el desarrollo, es mínimo lo que se conoce acerca del impacto de los sistemas judiciales sobre el desempeño económico ${ }^{37}$, como señala Jorge Correa Sutil, un respetado profesor de Derecho chileno, «no es fácil evaluar dónde se reflejan estos cambios [reformas judiciales]» debido a la insuficiencia de los estudios que evalúan el impacto de las reformas ${ }^{38}$. Se han realizado pocas investigaciones examinando las consecuencias de las reformas en la vida económica y política de los países que las han aplicado ${ }^{39}$. Con la observación de Correa Sutil en mente, el resto de este artículo examina la consecuencia de dos aspectos de la agenda de reforma judicial del Banco Mundial, la «independencia judicial» y el «acceso a la justicia», por medio de un estudio de caso sobre el impacto en la generación de políticas del reformado sistema judicial costarricense. De todas maneras, debe señalarse que el principal patrocinador de la reforma judicial en Costa Rica ha sido el Banco Interamericano de Desarrollo (BID) $)^{40}$. Los objetivos del BID son muy similares a los del Banco Mundial, especialmente en lo que respecta al acceso a la justicia y a la independencia judicial. Nuestro énfasis aquí tiene que ver con los objetivos del Banco Mundial debido a su enorme importancia tanto en América Latina como en el resto del mundo ya que sus amplios objetivos de desarrollo económico actualmente son compartidos por la mayoría de las otras agencias patrocinadoras de reformas.

36. Los programas para profesionalizar el gremio incluyen «incrementar las facultades de Derecho, garantizar que esas instituciones de enseñanza cuenten con los recursos necesarios y modificar el currículum para que refleje las demandas de una economía de mercado» (R. MESSICK, 1994: 18).

37. R. MESSICK (1994: 117).

38. J. CORREA SUTIL (1999: 256-257).

39. Esto está cambiando lentamente; ver, por ejemplo, la reciente serie de trabajos sobre el impacto de los programas de Administración de justicia producidos por la Carnegie Endowment for International Peace.

40. El gobierno de Costa Rica recibió dos préstamos del BID: uno de \$11,2 millones en 1995 destinado a financiar el Programa de Modernización de la Administración de justicia (Ley n. ${ }^{\circ} 7.496$ -Convenio de préstamo entre el gobierno de Costa Rica y el Banco Interamericano de Desarrollo n. ${ }^{\circ} 859 /$ OC-CR). Un segundo préstamo por $\$ 22,4$ millones el 18 de enero del 2002, inició la segunda etapa en el programa de reforma (Ley n. ${ }^{\circ} 8.273$, aprobación del préstamo n. ${ }^{\circ} 1377 /$ OC-CR). Costa Rica también recibió una ayuda técnica de cooperación equivalente a $\$ 1,13$ millones no reembolsables para establecer los mecanismos de Resolución Alternativa de Conflictos (RAC). La meta del primer préstamo del BID fue ayudar a «crear un Poder Judicial más equitativo, accesible y seguro, que permita a sus autoridades reducir el número de asuntos atrasados y superar el congestionamiento del sistema de justicia» (C. BIEBESHEIMER, 2001: 114 y 123). 


\section{El tradicional Sistema DE JUSTICIA EN COSTA Rica}

La actual Constitución Política de Costa Rica, promulgada al finalizar la guerra civil de 1948, incluye garantías a los derechos individuales, sociales y económicos ${ }^{41}$. Las reformas económicas concomitantes reposan sobre las bases de «un fundamento legal para un nuevo y moderno Estado con una incuestionable orientación intervencionista ${ }^{42}$, que permitió al Estado cumplir con su nuevo mandato constitucional ${ }^{43}$.

La nueva Constitución asignó al Estado un amplio protagonismo económico y social, redujo los poderes presidenciales, en cambio, reconoció a la Corte Suprema de Justicia como cabeza de uno de los tres poderes del Estado, con idéntico rango que el Ejecutivo y el Legislativo. El poder político fue extensamente distribuido en los poderes electos del gobierno, así como en el Tribunal Supremo de Elecciones (TSE), la Corte Suprema de Justicia y un amplio número de instituciones autónomas del Estado (IAs) ${ }^{44}$, sin embargo, la Corte Suprema no ejerció plenamente las funciones asignadas. En su lugar, la Corte consideró su papel como secundario ante los poderes electos del gobierno, por lo cual generalmente evitó intervenir en asuntos que involucraran funciones ejecutivas o legislativas, enfrentó severas limitaciones al pleno ejercicio de sus facultades constitucionales $^{45}$. Una limitación a la acción de la Corte Suprema fue el requerimiento de una mayoría de dos tercios de sus integrantes de la Corte para declarar la inconstitucionalidad de una ley, por lo cual si apenas se alcanzaba el voto de una mayoría simple de sus miembros la ley cuestionada seguiría surtiendo efectos. La segunda gran limitación a la acción de la Corte fue que ella operó bajo la tradición de la ley civil. En los sistemas de derecho civil, las Cortes Supremas parten del supuesto de que las Asambleas Legislativas son órganos soberc nos en la generación de políticas. En consecuencia, la Corte asumió la constitucionalidad de todas las leyes y decretos a menos que fueran evidentemente contrarios a las reglas constitucionales. Cuando la legislación contradecía el «espíritu de la ley», la Corte generalmente no intervenía, asumiendo una posición activa únicamente en casos donde la legislación resultaba explícitamente contraria a la «letra de la ley» interpretada en` 3 entido estricto. Estos factores, en parte enraizados en la cultura jurídica y política costarricense, limitaron la voluntad y la capacidad de intervenir en casos de inconstitucionalidad de leyes y decretos. Esto produjo un elevado nivel de inmovilismo judicial.

41. Constitución Política, artículos 20-74.

42. J. ROVIRA MAS (1989: 132).

43. Las reformas incluyeron la nacionalización de todo el sector bancario y la creación de una serie de instituciones autónomas del Estado encargadas de proveer recursos y servicios a precios favorables (L. BRENES, 1990; B. M. WILSON, 1998: 81-86).

44. B. M. WILSON (1998: 81-112).

45. B. M. WILSON y R. HANDBERG (2002: 365-371). 
BRUCE M. WILSON, JUAN CARLOS RODRÍGUEZ CORDERO Y ROGER HANDBERG A MAYORES PREVISIONES... RESULTADOS IMPREVISTOS:

REFORMA JUDICIAL EN AMÉRICA LATINA -INDICIOS SOBRE COSTA RICA

\section{LA REFORMA JUDICIAL EN COSTA RICA}

A partir de 1989 Costa Rica llevó a cabo uno de los más extensos programas de reforma judicial en América Latina. Mientras las motivaciones de las reformas generan algún desacuerdo, no hay duda sobre la extensión de las mismas ${ }^{46}$. Antes de las reformas, el papel de los tribunales en Costa Rica era reflejo de los tribunales del resto de América Latina. Pero los tribunales reformados, en especial la nueva cámara de control constitucional de la Corte Suprema, han sido muy activos. Como en las siguientes secciones se muestra, la independencia judicial fue establecida muchos años antes a las recientes reformas judiciales, pero históricamente la Corte había jugado un papel menor y tímido en la política costarricense, pues rara vez se atrevió a cuestionar las decisiones de los órganos del gobierno popularmente elegidos. Lo que cambió notablemente en el período posterior a la reforma fue el acceso a la justicia. El caso de Costa Rica indica que aunque una Corte Suprema goce de elevados niveles de independencia judicial, ello no significa que necesariamente vaya a actuar como efectivo contrapeso frente a los Poderes Ejecutivo y Legislativo del gobierno. Adicionalmente, la experiencia reciente sugiere que mejorar el acceso a la justicia puede producir el imprevisto efecto de que la acción de las cortes frustre varios tipos de políticas de libre mercado pretendidas por el Banco Mundial.

\section{LA CREACiÓN DE LA SALA IV}

La Ley n. ${ }^{\circ} 7.128$ del 18 de agosto de 1989 reformó los artículos $10,48,105$ y 128 de la Constitución Política de 1948. Se creó una cuarta cámara dentro de la Corte Suprema con una enorme autoridad para decidir, por mayoría simple, sobre la constitucionalidad de todas las normas y actos sujetos al derecho público. Adicionalmente, los siete miembros de la nueva cámara (magistrados) toman las decisiones por sí mismos, y no en sesiones plenarias con las otras tres cámaras de la Corte Suprema. Así la capacidad del Poder Judicial para declarar la inconstitucionalidad de leyes y acciones se incrementó significativamente.

Antes de la creación de la Sala IV, la amplia devaluación de poder político había propiciado la utilización de varias avenidas informales por parte de los grupos de interés y los ciudadanos para canalizar sus intereses específicos. Las peticiones podían dirigirse a los diputados de la Asamblea Legislativa, al presidente, a su gabinete o a los presidentes ejecutivos de las importantes instituciones autónomas y semiautónomas. Pocos individuos, grupos o partidos tomaban en cuenta a los tribunales como parte de su estrategia política. Por ejemplo, en los 51 años anteriores a la creación de la Sala IV, fueron tramitados por la Corte un total de 247 casos de inconstitucionalidad. Pero

46. B. M. Wilson, R. HANDBERG y R. S. BAKER (1991: 349-397); R. S. BAKER (2000). Sobre las reformas se ha escrito mucho y a menudo se encuentran referencias a ella como una «revolución judicial» (J. Córdoba Ortega et al., 1996: 9; J. Murillo VíQuez, 1994). 
desde la creación de la Sala Constitucional «prácticamente todo grupo de interés económico que haya sufrido una pérdida de sus anteriores protecciones o subsidios... ha acudido a la Sala IV ${ }^{47}$. En sus primeros 27 meses de existencia atendió más de 750 casos de inconstitucionalidad ${ }^{48}$. Este vertiginoso incremento en el número de casos revela una creciente voluntad por parte de la Corte de actuar agresivamente con miras a abrir el acceso al sistema judicial. También demuestra el reconocimiento ciudadano de la voluntad de la Corte a tramitar y resolver una extensa variedad de casos.

El deber fundamental de la Sala IV es garantizar la supremacía de las normas y principios constitucionales, el derecho internacional y del ordenamiento jurídico vigente en la República, su uniforme interpretación y la aplicación de los derechos y libertades fundamentales consagrados en la Constitución y en los tratados internacionales vigentes en Costa Rica ${ }^{49}$. Según el artículo 48 de la Constitución, la Corte debe intervenir en contra de los abusos del Legislativo, del Ejecutivo y de los poderes burocráticos así como de los actos inconstitucionales de individuos privados o de algún otro acto que impida a cualquier persona el ejercicio legítimo de sus derechos consagrados por la Constitución ${ }^{50}$.

La reforma de 1989 confirió a la Corte amplias prerrogativas constitucionales y le estableció una serie de nuevos lineamientos institucionales. Estas reglas permitieron a los jueces extender su función en la protección de los principios constitucionales y los derechos individuales. Entre los más importantes poderes de la Sala IV se encuentra el de conocer y dictar resoluciones inapelables sobre toda cuestión de constitucionalidad y sobre acciones de otros poderes gubernamentales, de organismos del Estado o de individuos. La Corte, el zonsecuencia, goza de una gama mucho más amplia de poderes y de una autoridad mayor que la esperada en los sistemas de derecho civil, que generalmente son más restrictivos respecto al papel del Poder Judicial en los asuntos sociales y políticos.

En particular, la Sala tiene amplias facultades para tramitar recursos de bábeas corpus que le permite atender gestiones presentadas sin formalidades tales como la asesoría de un abogado. Adicionalmente, el artículo 48 de la Constitución establece el recurso de amparo, que constituye un mecanismo de protección de los derechos fundamentales más general que el hábeas corpus ${ }^{51}$. El amparo tiene como objeto mantener o

47. L. GUDMUNDSON (1996: 84-85).

48. El número de casos resueltos en esos dos períodos se incrementó de 327 (en 51 años desde la nueva Constitución) a 293 en los primeros 27 meses de existencia de la Sala, lo que representa un incremento de 26 veces (J. MuRILlo VíqueZ, 1994: 73).

49. Artículo $10^{\circ}$ de la Ley de la Jurisdicción Constitucional.

50. En las secciones IV y $\mathrm{V}$ de la Constitución Política se incluyen los derechos individuales y sus garantías, así como los derechos sociales y sus garantías. Estas garantías son mucho más amplias que las contenidas en el Bill of Rights de los Estados Unidos.

51. El recurso de amparo, contenido en el artículo 48 de la Constitución Política, garantiza a cualquiera, sin distinción alguna, el derecho a acudir a la Sala con el objeto de mantener o restablecer todos los derechos establecidos en la Constitución, salvo los incluidos bajo la protección del bábeas corpus. 
reestablecer todos los derechos constitucionales, por lo cual cualquier acto, norma, decreto, orden o ley contraria a la Constitución puede ser impugnada ante la Sala IV. Además, ella tiene la facultad de resolver los conflictos de competencia entre los distintos poderes del Estado ${ }^{52}$. Incluso puede conocer sobre la constitucionalidad de los proyectos de ley. La Sala IV reúne la más amplia combinación posible de discrecionalidad judicial con poderes que abarcan una revisión judicial abstracta, concreta y $a$

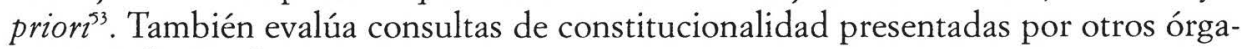
nos jurisdiccionales.

$\mathrm{Al}$ incrementar el número total de magistrados de 17 a 22 mejoró la efectividad de la Corte Suprema de Justicia. Siete magistrados conforman la Sala IV, mientras que las otras tres salas cuentan con cinco cada una. La diferencia en el personal de la nueva Sala indica que los legisladores previeron su elevado nivel de trabajo. Sin embargo, en el momento de su aprobación ninguno era consciente del enorme potencial e importancia que tendría para la vida económica y política del país.

\section{INDEPENDENCIA JUDICIAL}

La independencia judicial constituye uno de los objetivos principales del Banco Mundial y de otros IFIs patrocinadores de programas de reforma judicial. Como señala Fernando Carrillo, consultor del BID, «la piedra angular de la reforma es la efectiva independencia judicial [...]. Sin independencia judicial no hay imperio de la ley, y sin el imperio de la ley no es posible la consolidación de condiciones para el funcionamiento eficiente de una economía abierta» ${ }^{54}$. De cualquier modo, el caso de Costa Rica sirve para ilustrar que la independencia política formal y financiera para el Poder Judicial no necesariamente resulta ser un aliciente a las reformas neoliberales de libre mercado. A efectos de evaluar el impacto económico de la independencia judicial, Costa Rica resulta un excelente caso de estudio, pues su Corte Suprema de Justicia disfrutó tanto de independencia política como financiera muchos años antes de la creación de la Sala IV en $1989^{55}$.

La independencia judicial es muy difícil de medir en términos absolutos. De todas maneras, si se mira como un continuo, existen varios grados de independencia permitidos a los poderes judiciales en sus distintas manifestaciones. En el caso de Costa Rica, el Poder Judicial ha disfrutado de un elevado nivel de independencia respecto a los poderes popularmente elegidos del gobierno desde finales de la Guerra Civil de 1948. La

52. Entre las demás funciones de la Sala IV, el artículo 10 de la Constitución Política incluye la de escuchar propuestas concernientes a reformas constitucionales, aprobar convenciones o tratados internacionales y otros proyectos de conformidad con la ley. Este tipo de «intervención judicial previa» sólo ocurre en Costa Rica, Chile, Moldavia, República de África Central y Suiza (J. C. RoDríguEZ CORDERO, 2002a: 15-28; J. C. RODRIGUEZ CORDERO, 2001).

53. A. R. BREWER-CARÍAS (1989).

54. E. JARQUín y F. CARRILLO (1998).

55. P. Russell y D. M. O'Brien (2001). 
Asamblea Legislativa elige a los magistrados de la Corte por períodos de ocho años, lo cual podría parecer que deja un gran espacio a una potencial interferencia política, sin embargo, otras normas atenúan esa posibilidad. Por ejemplo, para ser nombrado magistrado se debe recibir el apoyo de dos terceras partes de los diputados de la Asamblea Legislativa, lo cual inevitablemente obliga a acuerdos entre los diferentes partidos políticos que integran el Congreso ${ }^{56}$. Una vez elegidos, los nombramientos de los magistrados se renuevan automáticamente por ocho años más, a menos de que dos terceras partes de los diputados de la Asamblea Legislativa voten por remover al magistrado ${ }^{57}$, situación que nunca ha ocurrido desde la fundación de la Sala Constitucional. La independencia de los magistrados se consolida debido a que los diputados sirven por períodos de cuatro años y no pueden ser reelegidos en sus $\operatorname{cargos}^{58}$. La posibilidad de que los mismos diputados ocupen cargos en la Asamblea Legislativa al momento de nombrar a un magistrado y al momento de renovar ese nombramiento ocho años después - lo cual podría proveer la oportunidad de castigar a un magistrado por sus decisiones durante el ejercicio de su cargo- es bastante improbable. De esa manera a los magistrados de la Corte Suprema de Justicia se les asegura su estabilidad laboral de manera efectiva y necesariamente son juristas altamente cualificados que requieren el apoyo mayoritario de los partidos políticos a fin de ser nombrados en sus cargos. La independencia judicial se consolida aún más debido a la facultad exclusiva de los magistrados para nombrar a los jueces de todos los tribunales inferiores.

$\mathrm{La}$ independencia financiera constituye un segundo aspecto importante de la independencia judicial. En el cazo de Costa Rica, al Poder Judicial se le garantiza al menos un $6 \%$ del presupuesto ordinario anual del Estado ${ }^{59}$. Históricamente, el Poder Judicial ha recibido siempre una suma tan sólo ligeramente inferior a ese porcentaje constitucional, lo cual ha garantizado un inusualmente elevado nivel de independencia financiera, especialmente si se le compara con otros tribunales de la región.

La efectiva estabilidad laboral de los magistrados, su independencia financiera y su poder para nombrar a todos los jueces que integran los tribunales adscritos a la Corte Suprema de Justicia, les otorga un considerable nivel de independencia tanto hacia las presiones del gobierno como de la sociedad. La tradicional inactividad de los formalmente autónomos poderes judiciales indujo al Banco Mundial a impulsar una mayor independencia judicial política y financiera, como condición para una más efectiva generación de políticas económicas, sin embargo, no es posible predecir qué uso darían los magistrados a esa independencia. Así, la Corte Suprema de Justicia costarricense, que goza de uno de los más altos niveles de independencia judicial en América Latina,

56. J. C. RODRíguez CORDERO (2002b).

57. Constitución Política (artículo 158).

58. En 1999 se pretendió que la Sala IV anulara esta prohibición de reelección presidencial, sin embargo la gestión fue declarada sin lugar en el 2000 (J. C. RODRíguez CORDERO, 2002a: 94-95). La Sala IV volvió a estudiar el tema en el 2003 y declaró que la prohibición era inconstitucional. Como consecuencia de esta resolución, los ex presidentes pueden buscar la reelección ocho años después de haber finalizado su primer período en ejercicio.

59. Constitución Política (artículo 177). 
BRUCE M. WILSON, JUAN CARLOS RODRÍGUEZ CORDERO Y ROGER HANDBERG

A MAYORES PREVISIONES... RESULTADOS IMPREVISTOS:

REFORMA JUDICIAL EN AMÉRICA LATINA -INDICIOS SOBRE COSTA RICA

escogió jugar un papel menor en la vida política y económica del país. Un examen de la amplia gama de sucesivas políticas económicas de los distintos gobiernos pone en evidencia algunas situaciones en las que se hubiera esperado una valoración de constitucionalidad de esas políticas por parte de una Corte Suprema autónoma. Sin embargo, hasta la creación de la Sala IV la Corte Suprema costarricense permaneció sumida en la inercia.

\section{LA CORTE Y LAS POLÍTICAS ECONÓMICAS ANTES DE LA REFORMA JUDICIAL}

Es posible distinguir tres fases en la política económica costarricense entre 1948 y 1989 que en conjunto condujeron a la consolidación de un modelo de desarrollo económico impulsado por el Estado. Una cuarta fase, tratada en la siguiente sección, se caracteriza por el gradual abandono de ese modelo durante las décadas de 1980 y 1990 , hasta la adopción de los principios de una estrategia económica neoliberal. En la primera fase (1948-1963), sobresale el énfasis en el libre mercado bajo los límites de un incipiente modelo agro-exportador impulsado por un Estado dirigista, que nacionalizó los bancos y las demás instituciones financieras. La ciudadanía recibió con extrañeza estas políticas, las encontraban punitivas y dudaban acerca de la autoridad del gobierno para imponerlas. A pesar de ello, no prosperó ninguna acción legal en contra de las acciones gubernamentales. En la segunda fase (1963-1972), el Estado propició la industrialización endureciendo la regulación económica, introdujo el control de precios sobre productos y servicios básicos y estableció cargas impositivas a fin de proteger a las nacientes industrias domésticas. Todas estas medidas alejaron a Costa Rica de las expectativas de libre mercado que según el diseño de las reformas del Banco Mundial debían aparecer como consecuencia de un Poder Judicial autónomo. En el transcurso de la siguiente etapa (1972-1982) el Estado extendió considerablemente su papel económico y social, especialmente mediante la intensa distribución de servicios sociales como la salud y la educación. El Estado se consolidó también como uno de los mayores patronos del país, debido al acelerado crecimiento del sector público. La sólida posición del Estado le colocó como importante competidor de muchas empresas privadas cuyo crecimiento previo había sido estimulado por iniciativa estatal ${ }^{60}$.

Durante esta fase, las políticas económicas del gobierno casi nunca fueron cuestionadas por el Poder Judicial. Los grupos de interés afectados por las políticas del gobierno evitaban acudir a la vía jurisdiccional; en su lugar utilizaron las tradicionales estrategias de presión para expresar su descontento con las políticas o para disminuir su impacto. Los tribunales, a su vez, nunca limitaron las acciones del gobierno, aun cuando ellas fueran evidentemente punitivas. Inocente Castro, un reconocido abogado costarricense, opina que el impresionante número de acciones de inconstitucionalidad tramitadas ante el Poder Judicial a partir de la creación de la Sala IV

60. E. DORYAN GARRÓN (1990). 
BRUCE M. WILSON, JUAN CARLOS RODRÍGUEZ CORDERO Y ROGER HANDBERG

A MAYORES PREVISIONES... RESULTADOS IMPREVISTOS:

REFORMA JUDICIAL EN AMÉRICA LATINA -INDICIOS SOBRE COSTA RICA

se debe a que durante 170 años la actuación gubernamental se había despreocupado de las normas constitucionales ${ }^{61}$.

\section{ACCESO A LA JUSTICIA}

La verdadera innovación del proyecto de reforma judicial costarricense, según lo dicho, no radica tanto en la independencia judicial, sino en la ampliación del acceso a la justicia pues ha tenido un efecto mucho más profundo sobre las políticas económicas. La creación de la Sala IV en 1989 abrió a los grupos de interés y a los partidos políticos de oposición una amplia vía para influir y limitar la acción política del gobierno. Acudir al Poder Judicial se convirtió en una estrategia fundamental tanto para los grupos de interés como para los partidos políticos ${ }^{62}$. Desde la perspectiva de los partidos políticos de oposición, la vía jurisdiccional llegó a convertirse en un poderoso instrumento táctico para atrasar o anular proyectos de ley tramitados en la Asamblea Legislativa. Ello resultó especialmente relevante después de las elecciones del 2002, en la cuales ningún partido político obtuvo la mayoría en la Asamblea Legislativa, mientras que tres partidos políticos cuentan con suficientes diputados (diez) para enviar cualquier proyecto a consulta de constitucionalidad ante la Sala IV.

Aparte del incremento en el acceso de la clase política a la jurisdicción constitucional, la Sala IV ha realizado campañas publicitarias masivas explicando los contenidos de la Constitución y los potenciales remedios judiciales que los ciudadanos, o cualquier persona en Costa Rica, tienen a disposición para enfrentar sus problemas. Numerosos carteles informativos han sido colocados en los edificios públicos con explicaciones sobre los derechos y las garantías constitucionales. Además, la Sala abandonó rápidamente la añeja adhesión a formalismos procedimentales tan propia de la práctica del Poder Judicial antes de la reforma, en su lugar, se disminuyó al mínimo la nómina de requerimientos para la tramitación de asuntos. La Sala IV entró a conocer recursos de amparo y de hábeas corpus provenientes de cualquier ciudadano o habitante, en cualquier idioma, escrito sobre cualquier medio, sin necesidad de patrocinio letrado, conocimiento legal o pago de especies fiscales ${ }^{63}$. Así, se logró que el acceso al sistema judicial fuera lo más amplio posible.

Uno de los primeros casos presentados ante la nueva jurisdicción constitucional provino de un vendedor de granizados, Trinidad Ortega Fuentes, comúnmente conocido como «Don Trino». El ministro de Seguridad, Rogelio Ramos Pinto, había dispuesto que dicho señor no podría seguir vendiendo en su lugar habitual, la acera adyacente al edificio de la Asamblea Legislativa, durante la realización de una reunión de los jefes de Estado de las Américas. Don Trino presentó un recurso de amparo ante la Sala IV,

61. Semanario Universidad, n. ${ }^{\circ}$ 934, San José, Costa Rica, 9 de julio de 1990.

62. J. C. RODRíguEz CORDERO (2001).

63. Otros tipos de asuntos, como las cuestiones de constitucionalidad, requieren el cumplimiento de más formalidades legales. 
BRUCE M. WILSON, JUAN CARLOS RODRÍGUEZ CORDERO Y ROGER HANDBERG A MAYORES PREVISIONES... RESULTADOS IMPREVISTOS:

REFORMA JUDICIAL EN AMÉRICA LATINA -INDICIOS SOBRE COSTA RICA

la cual rápidamente resolvió a su favor ${ }^{64}$. Muy pronto los costarricenses reconocieron que la Sala podía servir como un eficiente y efectivo árbitro para la resolución de sus conflictos con la autoridad pública.

GRÁFICO I

CASOS PRESENTAdOS y RESUELTOS POR LA SALA IV, 1990-2002

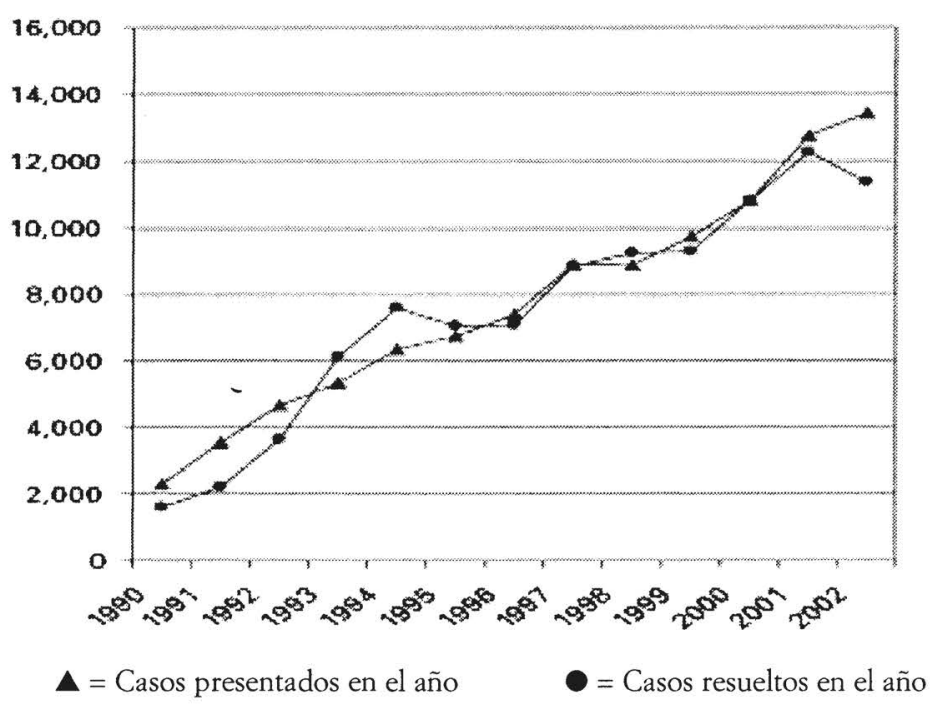

Fuente: Poder Judicial. Sección de Estadísticas del Departamento de Planificación y Sala Constitucional de la Corte Suprema de Justicia. San José, 2003.

El Gráfico I ilustra el meteórico incremento en el número de casos conocidos por la Sala IV desde su creación ${ }^{65}$. En su primer año de funcionamiento fueron tramitados 1.372 recursos de amparo (mecanismo de protección de los derechos fundamentales) y aproximadamente 290 acciones de inconstitucionalidad. En el 2002, el último año del cual disponemos datos completos, fueron tramitados más de 11.665 recursos de amparo y 289 acciones de inconstitucionalidad. El número agregado de casos tramitados se incrementó de 2.296 en 1990 a 13.431 en el 2002. Este enorme aumento en el número de personas que buscan remedio jurídico por medio de la Sala refleja tanto un éxito en el objetivo de facilitar el acceso a la justicia, como un inesperado cambio en

64. En este caso la Sala IV resolvió que la decisión del ministro de Seguridad denegaba a Don Trino su derecho constitucional a la libertad de trabajo (Constitución Política, artículo 46). Expediente n. ${ }^{\circ} 97-89$, resolución n. $^{\circ} 71-89$.

65. No es claro cuántos de estos casos han sido presentados por individuos y cuántos por grupos de interés. Lo que sí es definitivo es que el número total de casos refleja la creciente importancia de la Sala IV en la vida política del país. 
los cálculos políticos de los individuos y de los grupos de interés. En otras palabras, cada vez es más frecuente que los individuos prefieran acudir al remedio jurisdiccional representado por la Sala IV en lugar de los métodos tradicionalmente utilizados para la defensa de sus intereses. Este importante incremento en el acceso a procedimientos judiciales inexistentes antes de la reforma pone de manifiesto el logro de una de las metas del Banco Mundial, el acceso a la justicia ${ }^{66}$.

\section{El IMPACTO DE LA REFORMA JUDICIAL EN LA PRODUCCIÓN DE LA POLÍTICA ECONÓMICA, 1989-2002}

La reforma judicial en Costa Rica es una de las más extensas que se han llevado a cabo en América Latina y claramente cumple los objetivos del Banco Mundial y de otras IFIs y ONGs en cuanto a ampliar el acceso y fortalecer la independencia del Poder Judicial. Sin embargo, se ha estudiado muy poco si estos logros han tenido los efectos previstos por el Banco Mundial y por otros patrocinadores internacionales de la reforma judicial. Si bien la Sala IV actualmente resuelve más de 13.000 casos al año, los asuntos varían desde temas como la constitucionalidad de importantes leyes o los límites de la autonomía gubernamental para decidir sobre el gasto público, hasta la queja escrita a mano por un niño de diez años referente a las demoras de su autobús escolar ${ }^{67}$. La siguiente sección examina cuatro casos cruciales que han tenido o tendrán un impacto significativo sobre la capacidad de producción de políticas económicas por parte del Estado costarricense.

\section{El Código de Trabajo}

El Código de Trabajo de 1943 constituye un caso típico de una ley que resulta apegada a la letra pero no al espíritu de la Constitución Política. Este particular cuerpo normativo fue cuestionado por las organizaciones laborales durante más de cincuenta años ${ }^{68}$. Aunque la Constitución garantiza a los trabajadores el derecho a la sindicalización y a la huelga, también niega ese derecho a los empleados públicos. Tanto el Código de Trabajo como la Constitución reconocen el derecho a la huelga para los trabajadores del sector privado, pero el Código de Trabajo define como empleados públicos a todos aquellos que directamente trabajen para el Estado, a la mayoría de los

66. Las otras tres Salas de la Corte Suprema de Justicia también han experimentado incrementos considerables en el número de casos, pero no en la misma escala que la Sala IV. Según el Proyecto Estado de la Nación (2000), en 1999 las otras tres Salas de la Corte en conjunto votaron 1.164 recursos de casación (apelación final).

67. Este último caso -tramitado como amparo- tenía que ver con el derecho constitucional del niño a la educación gratuita. Según el recurrente, la compañía de autobuses lesionaba sus derechos constitucionales pues frecuentemente llegaba tarde. Expediente n. ${ }^{\circ}$ 5040-97.

68. Constitución Política (artículos 60 a 61). 
BRUCE M. WILSON, JUAN CARLOS RODRÍGUEZ CORDERO Y ROGER HANDBERG

A MAYORES PREVISIONES... RESULTADOS IMPREVISTOS:

REFORMA JUDICIAL EN AMÉRICA LATINA -INDICIOS SOBRE COSTA RICA

trabajadores agrícolas y a todos los que sean considerados como tales por el Poder Ejecutivo. Fernando Bolaños Céspedes, un especialista en derecho laboral, estima que esta definición del empleado público es demasiado amplia y que cubre el $70 \%$ de toda la fuerza laboral, privándoles así de su derecho a entrar en huelga ${ }^{69}$, a pesar de que éste es un derecho constitucionalmente garantizado. Esta inconsistencia no fue ignorada por las organizaciones laborales, que de manera repetida presionaron a los gobiernos de los dos partidos mayoritarios para reformar o derogar ese aspecto del Código Laboral. La imposibilidad de convocar a la huelga entre los empleados públicos fue especialmente relevante durante el período en que se comenzaron a aplicar las políticas neoliberales en respuesta a la crisis económica de los años ochenta, las cuales afectaron a los empleados públicos y a las organizaciones laborales debido a la reducción de puestos de trabajo y a la significativa caída de los salarios.

Los sindicatos intentaron convencer a los sucesivos gobiernos para que se reformara el Código de Trabajo: en 1982 al gobierno del Partido Liberación Nacional (PLN), en 1994 al del Partido Unidad Social Cristiana (PUSC) y, de nuevo, al PLN durante la administración de José María Figueres Olsen (PLN 1994-1998). Sin embargo, o los esfuerzos resultaron infructuosos o las reformas no se correspondieron con las demandas de las organizaciones de trabajadores ${ }^{70}$. La extensión del derecho a la huelga para el sector público se mantuvo como una posibilidad latente durante los sucesivos gobiernos que intentaron reducir el costo y tamaño del sector público en las décadas de 1980 y 1990.

En contraste, la Sala IV apareció como una nueva alternativa para que las organizaciones de trabajadores cuestionaran el Código de Trabajo, la cual pronto comprobó ser más efectiva que las estrategias políticas. En noviembre de 1992 cuatro sindicatos del sector público presentaron de manera conjunta una acción de inconstitucionalidad ante la Sala ${ }^{71}$. Los sindicatos tuvieron entonces la posibilidad de evitar los manejos políticos y, en su lugar, ofrecieron argumentos constitucionales ante la misma. La vía jurisdiccional resultó ser mucho más eficaz que los numerosos intentos políticos: el 28 de febrero de 1998, la Sala IV declaró inconstitucionales los artículos 376, incisos a), b) y e), y 389, párrafo segundo, del Código de Trabajo ${ }^{72}$. Consecuentemente, la limitación

69. La Nación, 04-03-1998.

70. Los líderes sindicales también solicitaron ayuda a la Organización Internacional de Obreros (ILO, por sus siglas en inglés) para presionar a los sucesivos gobiernos de Costa Rica para reformar el Código de Trabajo y ajustarlo a las normas de ILO. Una segunda estrategia, quizás más efectiva, consistió en acudir a la organización laboral estadounidense ALF-CIO. La ALF-CIO calificó de injustas las disposiciones del Código de Trabajo, presionó al Departamento de Estado Norteamericano para tratar de remover a Costa Rica de la lista de las naciones más favorecidas si no se reformaba el Código de Trabajo. Estas tácticas pretendían convencer a la Asamblea Legislativa sobre lo injusto de esas normas, pero finalmente los esfuerzos resultaron infructuosos.

71. Estas organizaciones obreras eran el Sindicato Industrial de Trabajadores Eléctricos y de Telecomunicaciones (SITET), el Sindicato de Trabajadores de JAPDEVA (SINTRAJAP), el Sindicato de Trabajadores de la División de Quepos (SINTRADIQUE) y el Sindicato de Ingenieros del Instituto Costarricense de Electricidad (SIICE).

72. Resolución n. ${ }^{\circ}$ 1317-98. 
del derecho a la huelga continuó vigente sólo para los trabajadores encargados de determinados medios de transporte y del sector salud, mientras que a todos los demás empleados públicos se les reconoció el derecho a la huelga ${ }^{73}$.

La creación de la Sala IV otorgó a los sindicatos una nueva alternativa para cuestionar el Código de Trabajo; su jurisprudencia efectivamente revitalizó a un movimiento que había sido sistemáticamente debilitado por gobiernos hostiles interesados en abandonar un modelo de intervención estatal en la economía para adoptar una estrategia de libre mercado de orientación neoliberal durante la década de 1980 y 1990 . El reconocimiento del derecho a la huelga también mejoró las posibilidades de negociación de los sindicatos públicos que fueron duramente golpeados por la crisis económica y por el proceso de reforma del Estado. El balance de poder cambió significativamente en muchos sentidos, así, en agosto de 1999 los empleados del Estado utilizaron su recientemente reconocido derecho a la huelga para reducir o detener muchos servicios públicos incluyendo hospitales, oficinas de la seguridad social, muelles, electricidad y comunicación telefónica. La huelga general terminó después de una semana, cuando el ministro de Trabajo, Víctor Morales, accedió a las demandas sindicales por un aumento salarial del $5,3 \%$, muy superior al originalmente ofrecido ${ }^{74}$. Lo relevante aquí es que la jurisprudencia de la Sala IV fortaleció la posición de los empleados públicos frente al Estado. Así la capacidad estatal para reducir el gasto público, que era lo pretendido por el Banco Mundial, fue severamente debilitada como consecuencia de la ampliación del acceso a la justicia que el mismo Banco Mundial y otras organizaciones internacionales habían propiciado mediante el impulso a la reforma judicial.

\section{PRivatización de las telecomunicaciones}

Otro de los temas tratados por la Sala IV se relaciona con uno de los aspectos incluidos en la agenda de desarrollo del Banco Mundial, el cual es la privatización de las empresas públicas. La producción y suministro de muchos de los recursos de Costa Rica fueron nacionalizados en la etapa inmediatamente posterior a la Guerra Civil. El monopolio de los servicios eléctricos y de telecomunicaciones fue asignado a una empresa pública denominada Instituto Costarricense de Electricidad (ICE) 75 . En 1987 (antes de la creación de la Sala IV), el gobierno intentó disminuir su intervención en la industria telefónica permitiendo a la compañía estadounidense Millicom ofrecer servicios de telefonía celular. Millicom obtuvo la concesión sin que prácticamente hubiera oposición legislativa y sin cuestionamientos sobre la legalidad de la medida.

73. La Nación, 04-03-98.

74. Tico Times, 06-08-99.

75. El monopolio incluye la producción y suministro de electricidad, aunque es posible que algunas pequeñas compañías privadas produzcan parte de la electricidad requerida por el país, siempre y cuando se la vendan al ICE. 
BRUCE M. WILSON, JUAN CARLOS RODRÍGUEZ CORDERO Y ROGER HANDBERG A MAYORES PREVISIONES... RESULTADOS IMPREVISTOS:

REFORMA JUDICIAL EN AMÉRICA LATINA -INDICIOS SOBRE COSTA RICA

Sin embargo, desde la perspectiva de los sindicatos del ICE la aparición de Millicom representaba el inicio de un proceso de privatización de servicios, lo cual iba en contra de sus intereses gremiales. Con la creación de la Sala Iv los sindicatos complementaron el uso de sus tradicionales mecanismos de presión a los diputados y al Poder Ejecutivo con la gestión para que la Sala IV examinara la constitucionalidad de la concesión. En octubre de 1993 la Sala IV aceptó el argumento de los sindicatos y declaró que el servicio de telefonía celular es un tipo de servicio telefónico, por lo cual estaba protegido por el monopolio estatal establecido en la Constitución. Consecuentemente, el intento del gobierno por abrir el mercado telefónico a empresas privadas fracasó. En este caso la jurisprudencia constitucional impidió al gobierno continuar con su estrategia de apertura en el mercado de las telecomunicaciones ${ }^{76}$. Como consecuencia de las resoluciones de la Sala se redujo la capacidad del gobierno para impulsar reformas neoliberales de apertura de mercados y consolidó la capacidad de influencia de los sindicatos. De nuevo, el efecto de un Poder Judicial más independiente y participativo ha obligado al gobierno a ajustarse a preceptos constitucionales que le obligan a permanecer inserto en la actividad económica del país, precisamente se dio lo opuesto al resultado previsto por el Banco Mundial ${ }^{77}$.

\section{CONTROL DE PRECIOS}

El control de precios constituye otra área en la cual la Sala Iv ha establecido líneas contrarias al incremento de la competencia y a políticas económicas de libre mercado. Tradicionalmente el control de los precios de bienes y servicios básicos, públicos o privados, constituye un componente crucial de las políticas sociales y económicas de los Estados. Estos controles de precios son objeto de frecuente manipulación por los gobiernos de acuerdo con intereses electorales. Sin embargo, esa herramienta electoral fue atacada a fines de 1996 por la Cámara Nacional de Comerciantes Detallistas que cuestionó la constitucionalidad de que la Autoridad Reguladora de los Servicios Públicos (ARESEP) regulara el precio del gas de uso doméstico ${ }^{78}$. A inicios de 1997 cuatro empresas privadas dedicadas al suministro de gas doméstico, incluyendo las dos más grandes (Gas Zeta y Gas Tropical), no atendieron las nuevas regulaciones gubernamentales sobre el precio del gas, sostuvieron que ese tipo de regulación era inconstitucional, y siguieron vendiendo el gas a un precio superior al establecido por el gobierno. Esas empresas de inmediato presentaron un recurso de amparo ante la Sala IV para anular los nuevos

76. La Nación, 15-30 de mayo de 1995; B. WiLSON (2002: 155).

77. La administración del doctor Miguel Ángel Rodríguez Echeverría (PUSC, 1998-2002) retomó el tema de la privatización del ICE. A la vez que se presentaban recursos ante la Sala IV en contra de la acción del gobierno, estalló una ola de protestas (con ocasionales brotes de violencia) a lo largo del país, paralizando la ciudad de San José. Nuevamente la Sala IV declaró inconstitucional el proyecto tramitado por la Asamblea Legislativa, debido a errores de procedimiento (Exp. 00-002411CO-E; Res. 00-03220).

78. La Nación, octubre de 1996. 
BRUCE M. WILSON, JUAN CARLOS RODRÍGUEZ CORDERO Y ROGER HANDBERG

A MAYORES PREVISIONES... RESULTADOS IMPREVISTOS:

REFORMA JUDICIAL EN AMÉRICA LATINA -INDICIOS SOBRE COSTA RICA

precios fijados por el Poder Ejecutivo ${ }^{79}$. Como respuesta, el ministro de Economía advirtió que se aplicarían sanciones a las cuatro compañías ${ }^{80}$.

Finalmente, la Sala IV rechazó la gestión de las compañías de gas y autorizó al Estado a continuar con sus políticas de intervencionismo económico. Aunque las empresas perdieran el caso, durante dieciocho meses lograron mantener en suspenso la fijación de precios dispuesta por el gobierno, hasta que la Sala IV resolvió el trámite de manera definitiva. A partir de esa experiencia, otros grupos de interés han utilizado esa misma táctica de acudir a la Sala IV para desafiar la política económica del gobierno. De hecho, durante la administración de Rafael Ángel Calderón Fournier (1990-1994), fueron presentados ante la Sala IV tal cantidad de casos contra distintos ministros del gobierno, que el Poder Ejecutivo tuvo que destinar recursos considerables a su defensa, lo cual prácticamente paralizó a algunos ministros claves. En consecuencia, los siguientes gobiernos se vieron obligados a prestar atención a los intereses económicos y sociales de quienes se oponían a sus políticas, a fin de evitar los potenciales costos de impugnaciones en la vía jurisdiccional. Sin embargo, fue aún más importante la jurisprudencia de la Sala IV a favor de las políticas de intervencionismo económico estatal y contra las aspiraciones de las empresas privadas por incrementar la competencia en un marco de libre mercado. De esa manera, se dieron resultados precisamente contrarios a los esperados por el Banco Mundial y otras IFIs.

\section{CONTROL DEL GASTO PÚBLICO}

La Constitución Política asigna ciertos porcentajes del presupuesto público a determinadas instituciones del Estado, como el Poder Judicial o las de educación superior $^{81}$. Estas disposiciones constitucionales no siempre son seguidas de manera estricta, especialmente en el caso de la Caja Costarricense de Seguro Social (CCSS), institución encargada de la salud pública, la cual regularmente ha recibido menos dinero que el correspondiente, sin importar cuál haya sido el partido político en el poder.

De manera similar, aunque la Constitución Política asigna al Poder Judicial el 6\% del presupuesto ordinario del Estado, en 1998 recibió únicamente el 5,75\%. Ante tal situación hubo amenazas de presentar un recurso ante la Sala IV para obligar al gobierno a cumplir con el porcentaje constitucional. La pugna puso en serio riesgo los márgenes de maniobra del gobierno a la hora de diseñar el presupuesto público. Por tal motivo el gobierno decidió atender las normas constitucionales antes de que fuera interpuesto algún recurso ante la Sala. De haberse presentado alguno, y si hubiera prosperado, todos los gobiernos siguientes se hubieran encontrado obligados a atender sus

79. La Nación, 19 de febrero de 1997.

80. Aunque la Sala IV posteriormente resolvió en contra de las compañías, en octubre de 1997 también anuló las sanciones aplicadas contra ellas.

81. Sobre este particular, las partes relevantes de la Constitución Política son: el artículo 177 sobre el Poder Judicial y los artículos 78, 84 y 85 sobre la educación superior. 
obligaciones constitucionales para con todas las demás instituciones, autónomas y semiautónomas, limitando su autonomía para la distribución de fondos.

Otros dos ejemplos de la jurisprudencia de la Sala IV demuestran cómo se le ha impedido al gobierno aplicar medidas económicas tendentes a reducir el gasto público. En ambos casos la Sala ha obligado al gobierno a ampliar los alcances del Estado de bienestar. A finales del 2002 la administración Pacheco (2002) ordenó disminuir el año académico de las escuelas primarias y colegios secundarios de 200 a 173 días lectivos, a fin de reducir los costos del ejercicio fiscal. La Sala dio trámite al asunto y declaró inconstitucional la medida del gobierno ${ }^{82}$. Como fundamento de su resolución dijo que Costa Rica debía cumplir con las condiciones del Convenio Centroamericano sobre la Unificación de la Educación Básica, tratado internacional del cual el país es signatario. Este tratado obliga a mantener un mínimo de 200 días lectivos por año. Como resultado de la resolución, el Estado tuvo que buscar los recursos necesarios para mantener abiertas las escuelas durante los 200 días lectivos requeridos.

Los costarricenses disfrutan de un servicio de salud universal que consume uno de los más amplios rubros presupuestarios. Al difundirse la pandemia del HIV-SIDA, la Caja Costarricense de Seguro Social (CCSS), como encargada del sistema de salubridad ciudadana, se negó a comprar ciertos medicamentos contra esa enfermedad, bajo el argumento de que el antiviral AZT no constituye una cura contra el SIDA y que tan sólo «prolongaría el curso del deterioro» ${ }^{83}$. En 1992 la Sala IV aceptó los argumentos de la CCSS y rechazó un recurso tendente a que se proporcionara la droga AZT a todos los pacientes infectados con el $\operatorname{SIDA}^{84}$. Cinco años después, en agosto de 1997, se dio curso a otro caso similar $^{85}$. Álvaro Salas, presidente ejecutivo de la CCSS, sostuvo que el tratamiento de los pacientes de SIDA utilizando esa droga era financieramente imposible pues con un costo de $\$ 800$ mensual por paciente se requerirían $\$ 1,8$ millones al año ${ }^{86}$. En esta ocasión la Sala IV resolvió en contra de la CCSS y obligó al Estado a proveer gratuitamente ese medicamento a todos los enfermos de SIDA con un nivel de células T inferior a 350 y a aquellos enfermos con probabilidades de infección ${ }^{87}$. Como en el caso de la educación, el gobierno se vio obligado a incrementar el gasto en servicios públicos aunque intentaba reducir esos costos. De esa manera, los intentos gubernamentales por reducir el tamaño del sector estatal, de conformidad con las metas de los organismos financieros

82. Expediente n. ${ }^{\circ}$ 02-008928-0007, resolución n. ${ }^{\circ} 11515-02$.

83. R. STERN y A. MATAMOROS (1999: 17-19, http://www.icaso.org/icaso/docs/stories_english.pdf, consultado el 23 de enero del 2004).

84. Resolución n. ${ }^{\circ} 280-92$.

85. Expediente n. ${ }^{\circ} 5778$-V-97.

86. Tico Times, 26-09-97, p. 12; La Nación, 16-04-97, p. 17; G. SORIANO (1997).

87. Resolución n. ${ }^{\circ}$ 5934-97. Aunque el acceso fue inmediato para las cuatro personas que interpusieron el recurso de amparo, la CCSS tardó en extender el mismo trato a todos los pacientes de SIDA. Otros 30 casos similares fueron archivados por la Sala IV antes de sentar el precedente que permitió el acceso inmediato a las medicinas. A finales de 1998 más de 400 pacientes estaban recibiendo medicamentos antirretrovirales a través del sistema de salud estatal (R. STERN, 1999: 3-4). 
BRUCE M. WILSON, JUAN CARLOS RODRÍGUEZ CORDERO Y ROGER HANDBERG A MAYORES PREVISIONES... RESULTADOS IMPREVISTOS:

REFORMA JUDICIAL EN AMÉRICA LATINA -INDICIOS SOBRE COSTA RICA

internacionales, fracasaron debido a las decisiones de la recientemente creada Sala IV, que dotó de un nuevo dinamismo al Poder Judicia ${ }^{88}$.

\section{CONClusiones}

La reforma del sistema judicial ha sido central en la agenda del Banco Mundial y de otras IFIs. Generalmente se ha argumentado que la reforma judicial es deseable en los países menos desarrollados por cuanto facilitarían las soluciones del libre mercado a los problemas económicos que, a su vez, servirían de contrapeso al estatismo. Para que las Cortes asuman ese nuevo papel, siguiendo ese razonamiento, es necesario garantizar la independencia judicial y un amplio acceso a la justicia.

El caso costarricense permite evaluar las premisas de ese argumento. La independencia judicial en Costa Rica precede en varias décadas a la expansión del acceso a la justicia. Sin embargo, ello por sí solo no garantiza el dinamismo del Poder Judicial. No fue sino a partir de las reformas que ampliaron el acceso a la justicia, cuando de manera activa la Sala IV comenzó a regular el desempeño de los órganos estatales popularmente elegidos, de conformidad con las pautas constitucionales. Por tal razón, el caso de Costa Rica pone de manifiesto que la independencia judicial por sí misma puede considerarse precondición necesaria para que los jueces corrijan las acciones inconstitucionales de los funcionarios popularmente elegidos, pero de ninguna manera garantiza ese resultado.

Por otra parte, el caso en estudio revela que aunque independencia judicial y amplio acceso a la justicia se presenten simultáneamente, no existe ninguna garantía de que los tribunales se comporten de la manera prevista por el Banco Mundial y otras IFIs, o sea, en actitud de promover las reformas económicas de libre mercado. De hecho, la Sala IV no se ha distinguido por promover el modelo de libre mercado y limitar el papel gubernamental, en su lugar, parece interpretar su novedosa función como la de defender la Carta Constitucional en todos sus aspectos. La Constitución Política de Costa Rica, como es usual en varios países latinoamericanos, consagra amplios derechos y libertades civiles y obliga al Estado a proveer varios bienes y servicios. Así, las decisiones de la Sala IV reflejan el contenido de la Constitución, más que una particular aproximación ideológica o económica a la problemática nacional.

$\mathrm{Al}$ reforzar esos derechos y obligaciones del Estado, se imponen costos al gobierno que le limitan en sus facultades de dirección de las políticas públicas. Por ejemplo, cuando la Sala IV resolvió en favor de las personas enfermas de HIV/SIDA obligó al Estado a asumir los costos del tratamiento y la mediación para todos los pacientes de esa enfermedad. La jurisprudencia que derrumbó la prohibición de huelga entre los empleados públicos contenida en el Código de Trabajo, alteró la balanza del poder a favor de

88. La historia completa de las personas portadoras del virus HIV/SIDA y de sus gestiones ante la Sala IV para obtener sus medicamentos por medio del sistema de salud estatal se relata en B. M. WiLSON y J. C. RODRÍGUEZ CORDERO, sin publicar. 
BRUCE M. WILSON, JUAN CARLOS RODRÍGUEZ CORDERO Y ROGER HANDBERG

A MAYORES PREVISIONES... RESULTADOS IMPREVISTOS:

REFORMA JUDICIAL EN AMÉRICA LATINA -INDICIOS SOBRE COSTA RICA

los sindicatos y complicó seriamente las intenciones del gobierno de privatizar las empresas públicas. Así, mientras los gobiernos han intentado reducir la intervención estatal en la vida económica y social del país (de conformidad con los objetivos de desarrollo a partir del libre mercado, propuestos por el Banco Mundial y otras IFIs), la nueva jurisdicción constitucional ha mostrado un inusitado activismo en la defensa del estatismo previsto por la Constitución Política, y ha ordenado al Estado a cumplir con su mandato constitucional como proveedor de recursos y servicios para el bienestar social. Ciertamente la Sala IV se ha convertido en protagonista de primer nivel en la vida política y económica costarricense, pero no en el sentido previsto por el Banco Mundial $\mathrm{u}$ otros organismos internacionales patrocinadores de la reforma. Todo parece indicar que los resultados políticos y económicos de las reformas judiciales están sujetos a niveles muchísimo más altos de contingencia en los particulares contextos constitucionales de cada país que lo que pudo haberse previsto en las etapas iniciales del proceso de reforma.

\section{BiBLIOGRAFÍA}

Amstrong, Patricia. Selected World Bank an IDB Judicial Reform Proyects. Washington D.C.: Lawyers Committee for Human Rights, 1997.

BAKER, Robert S. Judicial Review in Costa Rica: Evolution and Recent Developments. Presentado en la reunión de Latin American Studies Association. Miami, 2000.

BIEBesheImeR, Christina. Justice Reform in Latin America and the Caribbean: The IDB Perspective. En Domingo, Pilar y SIEDER, Rachel. Rule of Law in Latin America: The International Promotion of Judicial Reform. London: Institute of Latin American Studies, 2001, p. 23. BRENES, Lidiette. La nacionalización bancaria en Costa Rica: un juicio bistórico. San José: FLACSO, 1990.

BREWER-CARÍAS, Allan R. Judicial Review in Comparative Law. New York: Cambridge University Press, 1989.

BusCAGLIA, Edgardo et al. Judicial Reform in Latin America: A Framework for National Development. En Essays in Public Policy. Hoover Institution: Standford University, 1995, p. 2.

Buscaglia, Edgardo y Dakolias, María. Judicial Reform in Latin American Courts: The Experience of Argentina and Ecuador. World Bank Technical Paper, 1996, n. ${ }^{\circ} 350$, p. 41.

CarotHers, Thomas. The Rule of Law Revival. Foreign Affairs, 2001 a, vol. 77, n. ${ }^{\circ} 2$, p. 95.

- The Many Agendas of the Rule of Law reform in Latin America. En Domingo, Pilar y SiEDER, Rachel. Rule of Law in Latin America: The International Promotion of Judicial Reform. London: Institute of Latin American Studies, 2001b.

CARRILlo, Fernando. InterAmerican Development Bank. En JARQuín, Eduardo y CARRILlo, Fernando (eds.). Justice Delayed: Judicial Reform in Latin America. Interamerican Development Bank, Johns Hopkins University Press, 1998.

Córdoba Ortega, Jorge et al. Constitución Politica de la República de Costa Rica. San José: Asamblea Legislativa, Investigaciones Jurídicas S.A., 1996, p. 9.

CORREA SuTIL, Jorge. Judicial Reform in Latin America: Good News for the Unprivileged? En MÉNDEZ, Juan Eduardo et al. (eds.). The (Un)Rule of Law and the Underprivileged in Latin America. Notre Dame: University of Notre Dame Press, 1999, p. 256. 
BRUCE M. WILSON, JUAN CARLOS RODRÍGUEZ CORDERO Y ROGER HANDBERG A MAYORES PREVISIONES... RESULTADOS IMPREVISTOS:

REFORMA JUDICIAL EN AMÉRICA LATINA -INDICIOS SOBRE COSTA RICA

Dakolias, María. Legal and Judicial Reform: The Role of Civil Society in the Reform Process. En Domingo, Pilar y Sieder, Rachel. Rule of Law in Latin America: The International Promotion of Judicial Reform. London: Institute of Latin American Studies, 2001.

DOMINGO, Pilar y SIEDER, Rachel. Rule of Law in Latin America: The International Promotion of Judicial Reform. London: Institute of Latin American Studies, 2001.

Doryan Garrón, Eduardo. De la abolición del ejército al Premio Nobel de la Paz. San José: Editorial de la Universidad de Costa Rica, 1990.

FAundeZ, Julio. Legal and Technical Assistance. En FAundeZ, Julio (ed.). Good Governance and Law: Legal and Institutional Reform in Developing Countries. New York: St. Martin's Press, 1997, pp. 1-24.

GudmundSON, Lowell. Costa Rica: New Issues and Alignments. En DomínguEZ, Jorge I. y Loewenthal, Abraham (eds.). Constructing Democratic Governance: Latin America and the Caribbean in the 1990s. Baltimore: John Hopkins University Press, 1996, pp. 84-85.

HagGark, Stepan. The Politics of Adjustment: Lessons from the IMF's Extended Fund Facility. En KaHLER, Miles (ed.). The Politics of International Debt. Ithaca Cornell University Press, 1986.

HAMmergren, Linn. The Politics of Justice and Justice Reform in Latin America. Boulder: Westview Press, 1998.

- Diagnosing Judicial Performance: Toward a Toll to Help Guide Judicial Reform Programs, borrador de trabajo realizado para Transparencia Internacional (s/f).

Judicial Independence: What It Is, How It Can Be Measured, Why It Occurs. En http://www1.worldbank.org/publicsector/test/oldlegal/judicialindependence.htm.

KAHLER, Miles. International Financial Institutions and the Politics of Adjustment. En NeLSON, Joan et al. Fragile Coalitions: The Politics of Economic Adjustment. New Brunswick: Transactions Book, 1989, pp. 139-160.

Messick, Richard. Judicial Reform and Economic Development: A Survey of the Issues. The World Bank Research Observer, 1999, vol. 14, n. ${ }^{\circ} 1$.

MuRILlo VíQuez, Jaime. La Sala Constitucional: una revolución político-administrativa en Costa Rica. San José, 1994.

OBANDO, Jorge. The United Nations Development Programme. En JARQuín, Eduardo y CaRrillo, Fernando (eds.). Justice Delayed: Judicial Reform in Latin America. Interamerican Development Bank, Johns Hopkins University Press, 1998, pp. 143-144.

PNUD. PNUD to Help Developing Countries Enbance Human Security and Strengthen the Rule of Law: Press Release, 13 de noviembre del 2001.

PODER Judicial. Sección de Estadísticas del Departamento de Planificación y Sala Constitucional de la Corte Suprema de Justicia. San José, 2003.

Proyecto de Estado de la Nación. Costa Rica, 2000.

RODRÍGUEZ CORDERO, Juan Carlos. Las reformas constitucionales en el diseño del sistema político costarricense: el caso de la consulta preceptiva de constitucionalidad (1989-1997). Tesis de Maestría de la Universidad de Costa Rica, 2001.

- (Re)equilibrios políticos en Costa Rica: el poder constituyente y el control de constitucionalidad. South Eastern Latin Americanist, 2002a, vol. 45, n. ${ }^{\circ} 3$ y 4, pp. 15-28.

- Entre curules y estrados: la consulta preceptiva de las reformas constitucionales en Costa Rica. San José: CR, Investigaciones Jurídicas S.A., 2002b.

Rovira Mas, Jorge. Costa Rica en los años 80. San José: Porvenir, 1989, p. 132.

Russell, Peter y O'BRIEn, David M. Judicial Independence in the Age of Democracy: Critical Perspectives from Around the World. Charlottesville: University of Virginia Press, 2001. 
BRUCE M. WILSON, JUAN CARLOS RODRÍGUEZ CORDERO Y ROGER HANDBERG A MAYORES PREVISIONES... RESULTADOS IMPREVISTOS:

REFORMA JUDICIAL EN AMÉRICA LATINA -INDICIOS SOBRE COSTA RICA

Salas, Luis. From Law and Development to Rule of Law: New and Old Issues in Justice Reform in Latin America. En Domingo, Pilar y SiEder, Rachel. Rule of Law in Latin America: The International Promotion of Judicial Reform. London: Institute of Latin American Studies, 2001, p. 17.

SHIHATA, Ibrahin. Judicial Reform in Developing Countries and the Role of the World Bank. En The World Bank in a Changing World: Selected Essays and Lectures, 1995, vol. 3, p. 170.

SoRIANO, George. AIDS Victims Wins Right to Drugs. Tico Times, 1997, vol. III, n. 38.

STERN, Richard. Costa Rican AIDS Patient Condition Wins Drug Cocktail in High Court Ruling. Psychology International, 1999, vol. 10, n. ${ }^{\circ}$, pp. 3-4.

Stern, Richard y Matamoros, Antonio. Activists Win Supreme Court Challenge in Costa Rica en HIV/AIDS and Human Rights: Stories from the Frontlines. En http://www.icaso.org/ icaso/docs/stories_english.pdf. Junio 1999, pp. 17-19.

USAID. Guidance for Promoting Judicial Independence and Impartiality. Revised edition. Washington D.C.: Technical Publications Series, 2002.

- Center for Democracy and Governance (s/f).

- Rule of Law. En http://www.usaid.gov/democracy/rol.html.

VAKY, Paul. U.S. Agency for International Development. En JARQUín, Eduardo y CarRILlo, Fernando (eds.). Justice Delayed: Judicial Reform in Latin America. Interamerican Development Bank, John Hopkins University Press, 1998, p. 137.

VERNER, Joel. The Independence of Supreme Courts in Latin America: A Review of the Literature. Journal of Latin American Studies, 1984, vol. 16, n. ${ }^{\circ}$ 3, pp. 463-506.

Wilson, Bruce M. Costa Rica: Politics, Economics and Democracy. Boulder: Lynne Reinner Publishers, 1998, pp. 81-86.

Wilson, Bruce M. y HandberG, Roger. Costa Rica. En Kritzer, Bert (ed.). Legal Systems of the World. Santa Barbara: ABC-CLIO, 2002, pp. 365-371.

Wilson, Bruce M.; HANDBERG, Roger y BAKER, Robert S. Taking Constitutionalism Seriously: Costa Rica's Sala Cuarta. Florida Journal of International Law, 1991, vol. 3, n. ${ }^{\circ}$ 6, pp. 349-397.

World BANK. Governance and Development. Washington D.C., 1992.

- Governance: The World Bank's Experience. Washington D.C., 1994.

Soriano, George. aIDS Victims Wins Right to Drugs. Tico Times, 1997, vol. III, n. 38.

STERN, Richard. Costa Rican AIDS Patient Condition Wins Drug Cocktail in High Court Ruling. Psychology International, 1999, vol. 10, n. ${ }^{\circ} 2$, pp. 3-4. 